\title{
Post-fire mechanical properties of high strength steels
}

\author{
H. T. $\mathrm{Li}^{\mathrm{a}}$ and B. Young ${ }^{\mathrm{a} *}$
}

aDepartment of Civil Engineering, The University of Hong Kong, Hong Kong, China

*corresponding author, e-mail address: young@hku.hk

\begin{abstract}
High strength steels are becoming increasingly attractive for structural and architectural applications due to their superior strength-to-weight ratio which could lead to lighter and elegant structures. The stiffness and strength of high strength steels may reduce after exposure to fire. The post-fire mechanical properties of high strength steels have a crucial role in evaluating the residual strengths of these materials. This paper presents an experimental investigation on post-fire mechanical properties of cold-formed high strength steels. A series of tensile coupon tests has been carried out. The coupon specimens were extracted from cold-formed square hollow sections with nominal yield stresses of 700 and $900 \mathrm{MPa}$ at ambient temperature. The specimens were exposed to various elevated temperatures ranged from 200 to $1000{ }^{\circ} \mathrm{C}$ and then cooled down to ambient temperature before tested to failure. Stress-strain curves were obtained and the mechanical properties, namely, Young's modulus, yield stress $(0.2 \%$ proof stress $)$ and ultimate strength, of the cold-formed high strength steel materials after exposure to elevated temperatures were derived. The post-fire retention factors that obtained from the experimental investigation were compared with existing predictive equations in the literature. New predictive equations are proposed to determine the residual mechanical properties of high strength steels after exposure to fire. It is shown that the proposed predictive equations are suitable for both cold-formed and hot-rolled high strength steel materials with nominal yield stresses ranged from 690 to $960 \mathrm{MPa}$.
\end{abstract}

Keywords: Cold-formed; Elevated temperature; High strength steel; Mechanical properties; Post-fire; Tubular sections.

\section{Introduction}

High strength steels are being increasingly used in various structural applications, such as bridges, high-rise buildings and offshore structures. With advanced metallurgical and manufacturing technologies, high strength steel products with yield stress above $1300 \mathrm{MPa}$ are currently available in the steel market $[1,2]$. Structures might inevitably expose to fire hazards and the capacities of steel structural members are normally significantly reduced in fire. After the September 11 attacks, the mechanical properties of high strength steels at elevated temperatures have attracted much research attention [2-9], leading to a sound understanding of the behaviour of high strength steel materials in fire. On the other hand, after cooling from elevated temperatures to ambient temperature, the fire damage needs to be assessed from the structural safety point of view. It is crucial and necessary to decide whether the residual stiffness and strength of steel members are still sufficient for future utilization. The postfire mechanical properties of steels are essential for such evaluations.

In this study, research efforts are made in order to provide suitable rules to predict post-fire mechanical properties of high strength steels with nominal yield stresses ranged from 690 to $960 \mathrm{MPa}$. A series of tensile coupon tests was carried out to investigate the residual mechanical properties of cold-formed high strength steels after exposure to elevated temperatures up to $1000{ }^{\circ} \mathrm{C}$. The coupon specimens were extracted from cold-formed high strength steel square hollow sections with nominal yield stresses of 700 and $900 \mathrm{MPa}$ at ambient temperature. Postfire mechanical properties including the Young's 
modulus, yield stress and ultimate strength were obtained. The derived post-fire retention factors were compared with existing proposals in Gunalan and Mahendran [10], Qiang et al. [11, 12] and $\mathrm{Li}$ et al. [13] in order to evaluate their applicability to cold-formed high strength steels. Moreover, predictive equations are proposed to determine the residual mechanical properties of high strength steels after fire exposure. It is illustrated that the proposed predictive equations can be used for cold-formed and hot-rolled high strength steels with nominal yield stresses ranged from 690 to $960 \mathrm{MPa}$ of various steel grades.

\section{Experimental investigation}

\subsection{Test specimens}

Tensile coupon tests were conducted to investigate the residual mechanical properties of cold-formed high strength steels after exposure to fire. Coupon specimens were extracted from two cold-formed square hollow sections of different steel grades, i.e., H140 $\times 140 \times 6$ and V120 $\times 120 \times 4$. The nominal yield stresses $(0.2 \%$ proof stresses) of the sections are 700 and 900 $\mathrm{MPa}$, which were indicated by the letters $\mathrm{H}$ and $\mathrm{V}$ in their section labels, respectively. The nominal cross-sectional dimensions $D \times B \times t$ were $140 \times 140 \times 6$ and $120 \times 120 \times 4$, where $D, B$ and $t$ were the overall depth, width and thickness in millimetres, respectively. The coupon specimens were obtained from the centre of the face at $90^{\circ}$ angles from the weld face of the sections. The coupon dimensions were prepared in accordance with the ASTM [14] using $6 \mathrm{~mm}$ wide coupon with $25 \mathrm{~mm}$ gauge length. The chemical composition of the cold-formed high strength steels can be found in Ma et al. [1], which reported the ambient temperature material properties of the same batch of sections.

The specimens were labelled such that their nominal yield stress, thickness and exposed temperature can be easily identified, as shown in Tables 1-3. For example, the label H6-T500-R defines the following specimen. The first letter of the label indicates the nominal yield stress of the coupon specimen was $700 \mathrm{MPa}$. The following number shows the nominal thickness of the coupon specimen was $6 \mathrm{~mm}$. The following notation T500 indicates the specimen was exposed to an elevated temperature of 500 ${ }^{\circ} \mathrm{C}$. Finally, the letter " $\mathrm{R}$ ", if any, indicates it is a repeated test.

\subsection{Test setup and procedure}

An MTS high-temperature furnace, as shown in Fig. 1(a), was used to heat up the specimens to target temperatures. The furnace consists of three pairs of independent-controlled heating elements enabling to heat the specimens at a maximum rate of $100{ }^{\circ} \mathrm{C} / \mathrm{min}$ up to $1400^{\circ} \mathrm{C}$. The furnace was controlled and monitored by an MTS temperature controller. Two external thermocouples were mounted on the surface of the coupon specimens to measure the real-time temperature of the specimens.

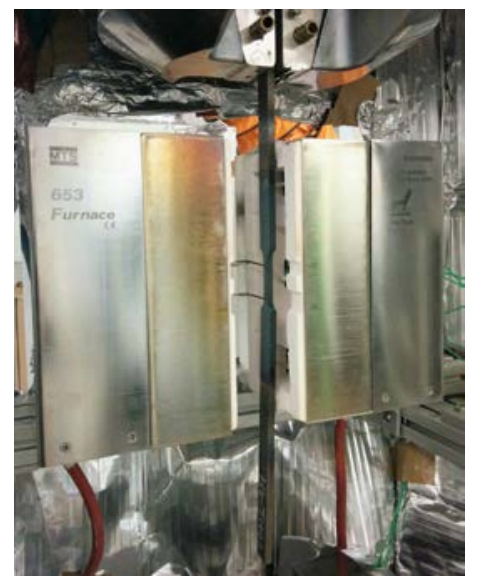

(a) Heating

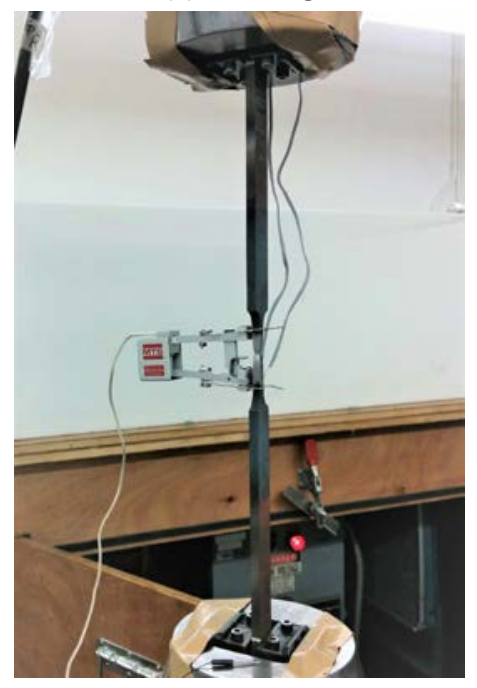

(b) Tensile testing

Fig. 1. Test setup.

A total of 11 different target temperatures was selected in this study. The selected temperatures were $20^{\circ} \mathrm{C}$ (ambient temperature), $200^{\circ} \mathrm{C}, 300{ }^{\circ} \mathrm{C}, 400{ }^{\circ} \mathrm{C}, 500{ }^{\circ} \mathrm{C}, 600^{\circ} \mathrm{C}, 700^{\circ} \mathrm{C}$, $750{ }^{\circ} \mathrm{C}, 800^{\circ} \mathrm{C}, 900^{\circ} \mathrm{C}$ and $1000^{\circ} \mathrm{C}$. The postfire coupon specimens were heated from ambient temperature to the specific target temperatures at a rate of $10^{\circ} \mathrm{C} / \mathrm{min}$. This heating rate has been reported to be similar to the rate of 
temperature increase for protected steelwork exposed to fire $[15,16]$. It is noteworthy that for all the post-fire coupon specimens, an additional 20 mins of soak time was employed after the target temperatures reached to ensure uniform temperature distribution could be obtained in the coupon specimens. During this heat soak period, the independent-controlled heating elements were adjusted to ensure the readings of the two external thermocouples, one near each end of the reduced section, stabilized within a difference of less than $1 \%$ compared to the target temperature. After the heat soak period, the furnace was deactivated and the coupon specimens cooled down in the furnace naturally. A data acquisition system was employed to record the time and temperatures at regular intervals during both the heating and cooling processes.

After the coupon specimens cooled down to ambient temperature, sandpapers were used to remove any oxide and coating that formed on the post-fire coupon surfaces. An MTS $50 \mathrm{kN}$ material testing machine was used to conduct the tensile coupon tests. All the post-fire tensile coupon tests were conducted at ambient temperature. As shown in Fig. 1(b), a calibrated MTS $25 \mathrm{~mm}$ gauge length extensometer and two strain gauges were used to measure the longitudinal strains of the post-fire coupon specimens. Displacement control was employed during testing and the coupon test procedures recommended by Huang and Young [17] were adopted herein. A data acquisition system was used to record the loads as well as the readings of the strain gauges and extensometer at regular intervals. The static stress-strain curves were obtained from the test curves using the method detailed in Huang and Young [17]. It should be noted that tensile coupon tests were also carried out on specimens H6-T20 and V4-T20, which were directly tested at ambient temperature without exposure to fire.

\section{Test results and discussions}

\subsection{Stress-strain curves}

The static stress-strain curves of the H6 (H140 $\times 140 \times 6$ section) and V4 (V120 $\times 120 \times 4$ section) series are shown in Figs. 2 and 3, respectively. The mechanical properties, namely, the Young's modulus $(E)$, yield stress $\left(f_{\mathrm{y}}\right)$ and ultimate strength $\left(f_{\mathrm{u}}\right)$, obtained from the tensile coupon tests that directly tested at ambient temperature are reported in Table 1.

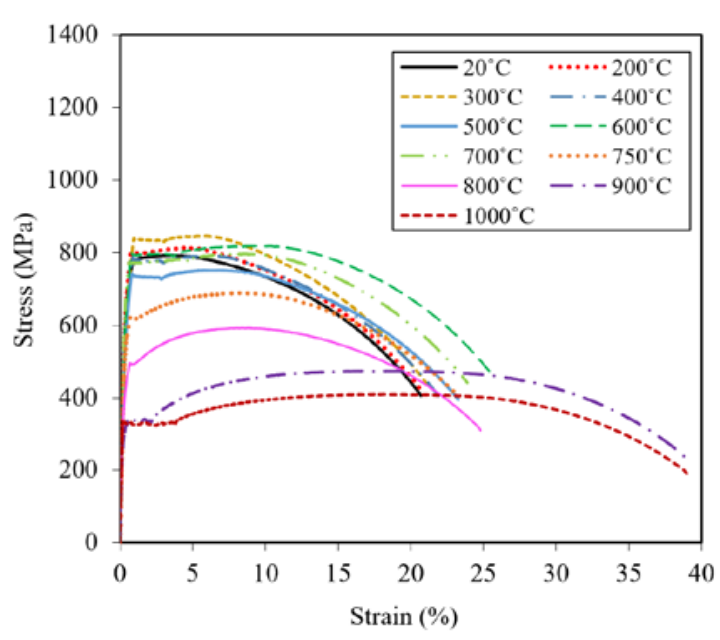

Fig. 2. Stress-strain curves of H6 series.

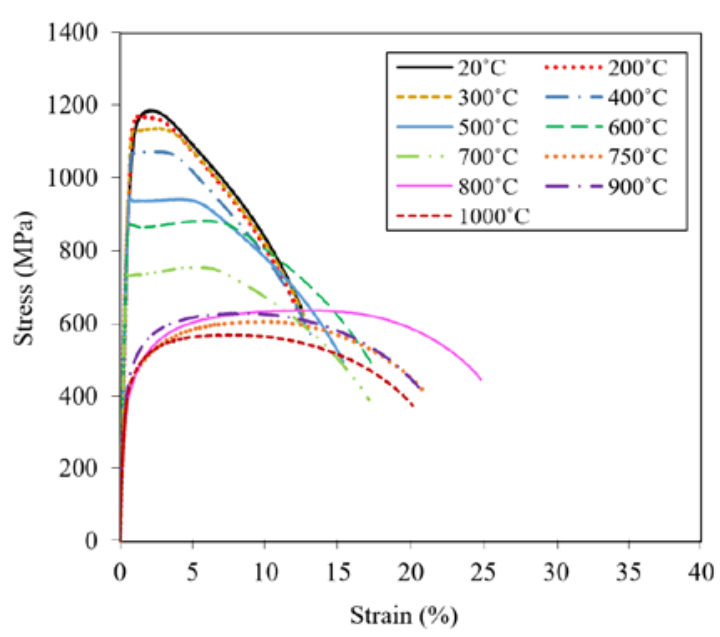

Fig. 3. Stress-strain curves of V4 series.

Table 1. Mechanical properties of cold-formed high strength steels at ambient temperature.

\begin{tabular}{cccc}
\hline Specimen & $E(\mathrm{GPa})$ & $f_{\mathrm{y}}(\mathrm{MPa})$ & $f_{\mathrm{u}}(\mathrm{MPa})$ \\
\hline H6-T20 & 213.4 & 673 & 793 \\
V4-T20 & 208.2 & 991 & 1187 \\
\hline
\end{tabular}

It is shown that the stress-strain curves at ambient temperature had gradual yielding, in other words, had no distinct yield plateau in the stress-strain curves. In this study, therefore, the $0.2 \%$ proof stress was taken as the yield stress of the high strength steel materials. Overall, the stress-strain curves obtained from the post-fire coupon specimens in the temperatures ranged from 300 to $1000{ }^{\circ} \mathrm{C}$ exhibited linear elastic regions followed by yield plateaus, except for the stress-strain curves for specimens of the V4 series in the range of 750 to $1000{ }^{\circ} \mathrm{C}$. Note that for the $\mathrm{H} 6$ series, the ductility of the material enhanced significantly after exposure to temperatures above $800{ }^{\circ} \mathrm{C}$. For the V4 series, 
the ductility of the material enhanced quite significantly at $800{ }^{\circ} \mathrm{C}$ compared to other 10 temperatures. It is also noteworthy that all the test specimens exhibited ductile failure undergoing necking before fracturing near the middle of the coupons, as shown in Fig. 4.

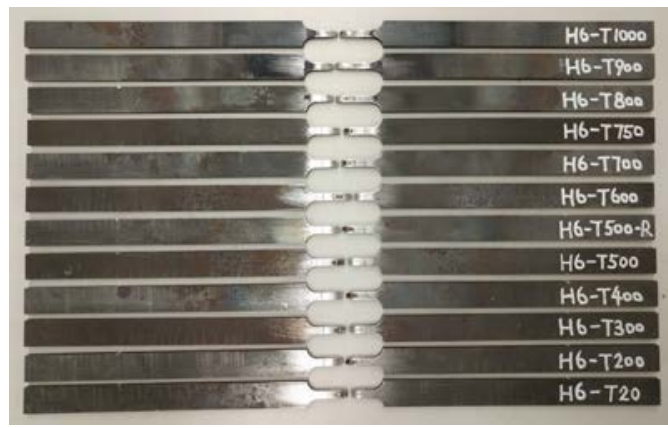

(a) H6 series

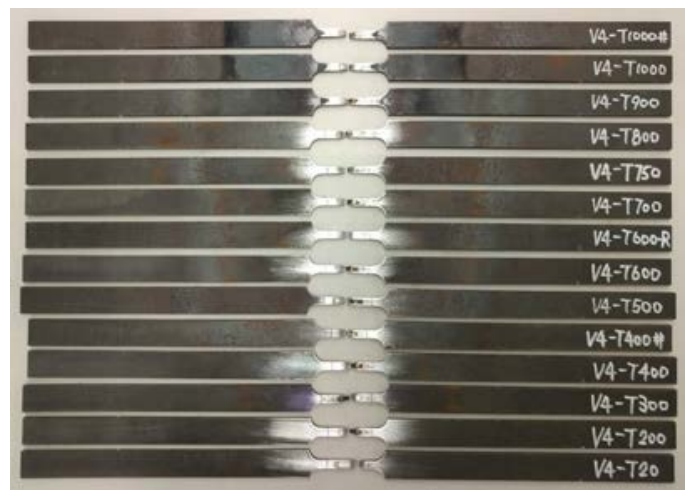

(b) V4 series

Fig. 4. Cold-formed high strength steel specimens after testing.

\subsection{Young's modulus}

The influence of fire exposure on the Young's modulus is discussed in this subsection. The post-fire retention factor of the Young's modulus was determined from the ratio of the residual Young's modulus $\left(E_{T}\right)$ after exposure to elevated temperature $T$ over the corresponding Young's modulus at ambient temperature $(E)$. The retention factors of the Young's modulus $\left(E_{T} / E\right)$ for $\mathrm{H} 6$ and V4 series are tabulated in Tables 2 and 3, respectively. The $E_{T} / E$ values are plotted and compared with the predictive equations proposed by Gunalan and Mahendran [10] for cold-formed high strength steel grades G500 and G550, Qiang et al. [11] for hot-rolled S690 steel sheet, Qiang et al. [12] for hot-rolled S960 steel sheet as well as Li et al. [13] for hot-rolled Q690 steel plate, as shown in Fig. 5.

Table 2. Post-fire retention factors for mechanical properties of H6 series.

\begin{tabular}{ccccc}
\hline Specimen & $T\left({ }^{\circ} \mathrm{C}\right)$ & $E_{T} / E$ & $f_{\mathrm{y}, T} / f_{\mathrm{y}}$ & $f_{\mathrm{u}, T} / f_{\mathrm{u}}$ \\
\hline H6-T20 & 21.3 & 1.000 & 1.000 & 1.000 \\
H6-T200 & 201.3 & 1.010 & 1.076 & 1.026 \\
H6-T300 & 300.9 & 1.016 & 0.991 & 1.067 \\
H6-T400 & 401.2 & 1.018 & 0.988 & 0.998 \\
H6-T500 & 498.7 & 1.017 & 0.914 & 0.948 \\
H6-T500-R & 501.2 & 1.013 & 0.916 & 0.954 \\
H6-T600 & 599.2 & 1.002 & 1.030 & 1.032 \\
H6-T700 & 699.6 & 1.022 & 1.126 & 1.005 \\
H6-T750 & 749.7 & 0.991 & 0.845 & 0.869 \\
H6-T800 & 800.1 & 0.982 & 0.647 & 0.747 \\
H6-T900 & 899.5 & 0.917 & 0.476 & 0.597 \\
H6-T1000 & 999.9 & 0.906 & 0.491 & 0.516 \\
\hline
\end{tabular}

Table 3. Post-fire retention factors for mechanical properties of V4 series.

\begin{tabular}{ccccc}
\hline Specimen & $T\left({ }^{\circ} \mathrm{C}\right)$ & $E_{T} / E$ & $f_{\mathrm{y}, T} / f_{\mathrm{y}}$ & $f_{\mathrm{u}, T} / f_{\mathrm{u}}$ \\
\hline V4-T20 & 21.6 & 1.000 & 1.000 & 1.000 \\
V4-T200 & 201.4 & 0.997 & 1.065 & 0.987 \\
V4-T300 & 300.3 & 1.002 & 1.084 & 0.959 \\
V4-T400 & 400.4 & 0.991 & 1.035 & 0.905 \\
V4-T500 & 501.2 & 1.008 & 0.951 & 0.795 \\
V4-T600 & 600.5 & 1.001 & 0.881 & 0.744 \\
V4-T600-R & 601.2 & 1.009 & 0.882 & 0.746 \\
V4-T700 & 700.2 & 1.008 & 0.738 & 0.637 \\
V4-T750 & 750.3 & 0.984 & 0.369 & 0.511 \\
V4-T800 & 800.8 & 0.964 & 0.354 & 0.537 \\
V4-T900 & 900.0 & 0.954 & 0.389 & 0.530 \\
V4-T1000 & 1000.0 & 0.899 & 0.368 & 0.481 \\
\hline
\end{tabular}

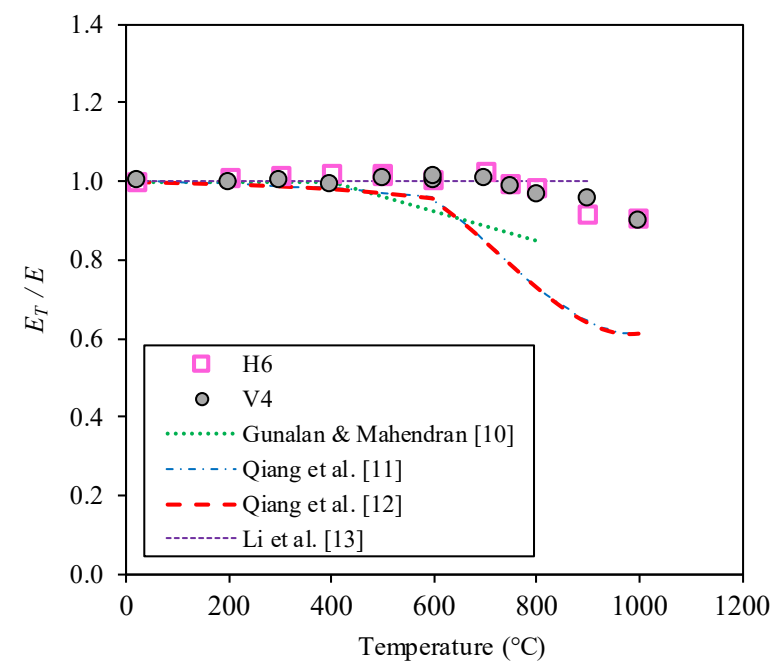

Fig. 5. Retention factors for Young's modulus of cold-formed high strength steels.

It can be observed that the cold-formed high strength steels regained more than $96 \%$ of their Young's modulus up to $800^{\circ} \mathrm{C}$, above which the deterioration became relatively more noticeable. Even after exposure to an elevated temperature of $1000{ }^{\circ} \mathrm{C}$, the cold-formed high strength steel 
materials were still able to regain about $90 \%$ of their Young's modulus at ambient temperature. It is shown that the predictive equations in Gunalan and Mahendran [10] and Qiang et al. $[11,12]$ could be conservatively used for the cold-formed high strength steels. The retention factors proposed by Li et al. [13] are taken as unity for temperatures up to $900^{\circ} \mathrm{C}$, which gives quite good predictions for the tested materials for temperatures up to $800{ }^{\circ} \mathrm{C}$.

\subsection{Yield stress}

The post-fire retention factor of the yield stress, which is taken as the $0.2 \%$ proof stress in this study, was determined from the ratio of the residual yield stress $\left(f_{\mathrm{y}, T}\right)$ after fire exposure to the corresponding yield stress at ambient temperature $\left(f_{\mathrm{y}}\right)$. The $f_{\mathrm{y}, T} / f_{\mathrm{y}}$ values are plotted against temperatures and compared with the predictive equations proposed by Gunalan and Mahendran [10], Qiang et al. [11, 12] and Li et al. [13] in Fig. 6.

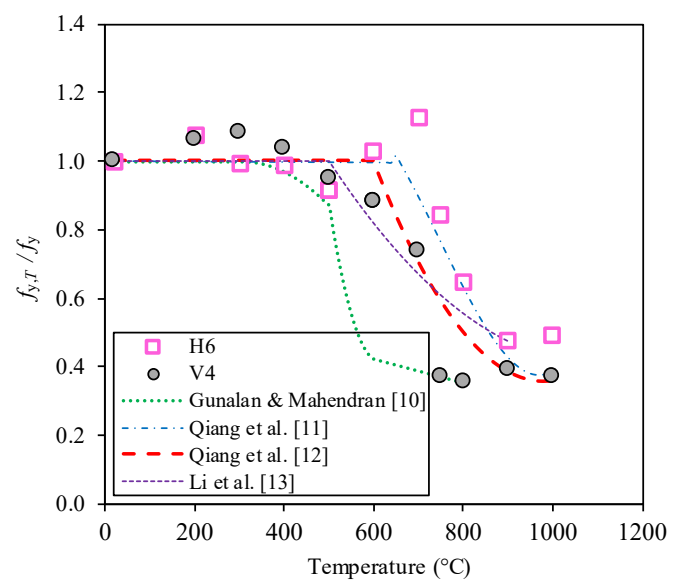

Fig. 6. Retention factors for yield stress of coldformed high strength steels.

The post-fire retention factors of the yield stress were greater than 0.91 for the $\mathrm{H} 6$ series up to $700{ }^{\circ} \mathrm{C}$, beyond which the yield stress deteriorated rapidly up to $900{ }^{\circ} \mathrm{C}$. For the V4 series, the yield stress retention factors remained generally unchanged for temperatures up to 500 ${ }^{\circ} \mathrm{C}$, and the cold-formed high strength steel regained more than $95 \%$ of its yield stress in this temperature range. For temperatures ranged from 500 to $700{ }^{\circ} \mathrm{C}$, the $f_{\mathrm{y}, \mathrm{T}} / f_{\mathrm{y}}$ ratio of the $\mathrm{V} 4$ series gradually reduced to 0.738 , after which a sudden drop to 0.369 was found at $750{ }^{\circ} \mathrm{C}$. For temperatures ranged from 750 to $1000{ }^{\circ} \mathrm{C}$, the deterioration of the yield stress remained at the same level with the discrepancy of the $f_{\mathrm{y}, T} / f_{\mathrm{y}}$ values within $3.5 \%$. Overall, the predictive equations proposed by Qiang et al. [11] for the S690 steel are able to provide conservative predictions for the H6 series. The predictive equations proposed by Qiang et al. [12] for the S960 steel give more conservative predictions than the rules in Qiang et al. [11] for temperatures ranged from 600 to $1000{ }^{\circ} \mathrm{C}$. The predictive equations proposed by Qiang et al. $[11,12]$ provide unconservative predictions for some of the data in V4 series especially for temperatures at 750 and $800{ }^{\circ} \mathrm{C}$. On the other hand, although providing accurate predictions for the V4 series for temperatures at 750 and 800 ${ }^{\circ} \mathrm{C}$, the proposal by Gunalan and Mahendran [10] give overly pessimistic predictions for the tested cold-formed high strength steels. Overall, the retention factors proposed by Li et al. [13] provide conservative predictions for the coldformed high strength steels up to $700{ }^{\circ} \mathrm{C}$, beyond which the proposal by $\mathrm{Li}$ et al. [13] overestimated the residual yield stresses for the V4 series.

\subsection{Ultimate strength}

The ultimate strength retention factor was determined from the ratio of the residual ultimate strength after heating and cooling down from the elevated temperature $\left(f_{\mathrm{u}, T}\right)$ to the corresponding ultimate strength at ambient temperature $\left(f_{\mathrm{u}}\right)$. The derived $f_{\mathrm{u}, T} / f_{\mathrm{u}}$ results were compared with the predictive equations proposed by Gunalan and Mahendran [10], Qiang et al. [12] and Li et al. [13] in Fig. 7.

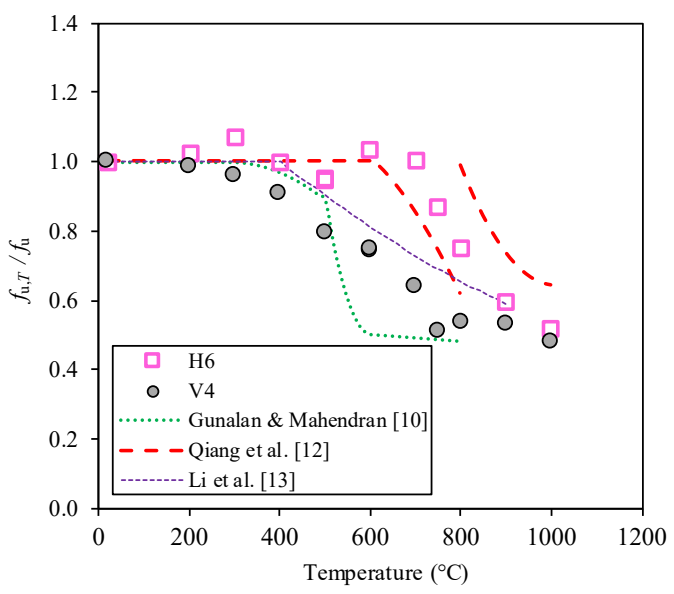

Fig. 7. Retention factors for ultimate strength of cold-formed high strength steels.

The $f_{\mathrm{u}, T} I f_{\mathrm{u}}$ values were close to unity for the H6 series up to $700{ }^{\circ} \mathrm{C}$, beyond which the residual ultimate strength reduced rapidly up to $1000{ }^{\circ} \mathrm{C}$. For the V4 series, the residual ultimate strength deteriorated gradually as temperature 
increased for temperatures up to $700{ }^{\circ} \mathrm{C}$. A relatively more rapid deterioration of the residual ultimate strength for the V4 series was found at $750{ }^{\circ} \mathrm{C}$, and beyond this temperature, the $f_{\mathrm{u}, T} / f_{\mathrm{u}}$ ratio generally remained similar with the values ranged from 0.481 to 0.537 . The predictive equations in Gunalan and Mahendran [10] provided overly conservative predictions for the H6 series, while gave unconservative predictions for the V4 series for temperatures up to $500{ }^{\circ} \mathrm{C}$. Qiang et al. [12] suggested discontinuous retention factors for the S960 steel, which aligns well with their own test data. However, this discontinuity proposed by Qiang et al. [12] could not compare well with the coldformed high strength steel data obtained in the present study. Overall, the retention factors suggested by Li et al. [13] provided conservative predictions for the $\mathrm{H} 6$ series, while providing unconservative predictions for the V4 series.

\section{Proposed predictive equations}

Predictive equations were proposed by Gunalan and Mahendran [10] for cold-formed G500 and G550 steels, Qiang et al. [11] for hotrolled S690 steel, Qiang et al. [12] for hot-rolled S960 steel and Li et al. [13] for hot-rolled Q690 steel to predict the post-fire mechanical properties of high strength steels. However, these proposals were calibrated with their own test data, which may restrain the applicability of being extended to other steel grades. In this study, predictive equations are proposed to determine the residual mechanical properties of high strength steels after exposure to fire. The cold-formed high strength steel data obtained in this study and the hot-rolled high strength steel data reported by Qiang et al. [11, 12], Li et al. [13] and Chiew et al. [18] were employed to propose the post-fire retention factors. Therefore, the predictive equations proposed in this study are not restricted to the materials that tested and reported herein, but can be applied for both cold-formed and hot-rolled high strength steels with nominal yield stresses ranged from 690 to $960 \mathrm{MPa}$ of various steel grades. The post-fire mechanical properties retention factors of the cold-formed high strength steels obtained herein are plotted together with those of the hotrolled high strength steels [11-13, 18] in Figs. 810.

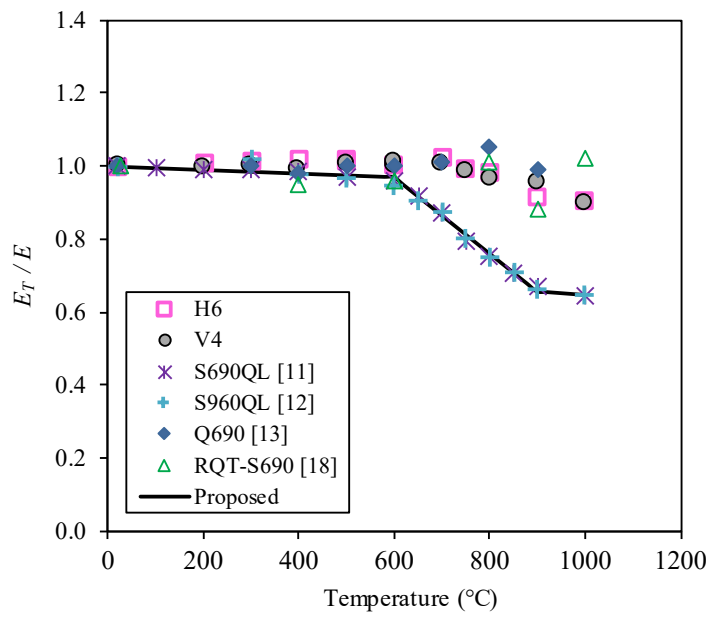

Fig. 8. Proposed Young's modulus retention factors for high strength steels.

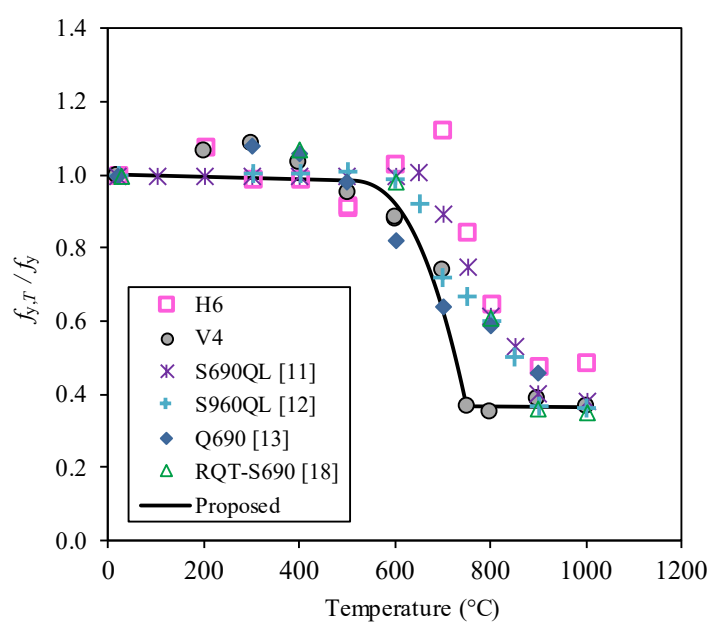

Fig. 9. Proposed yield stress retention factors for high strength steels.

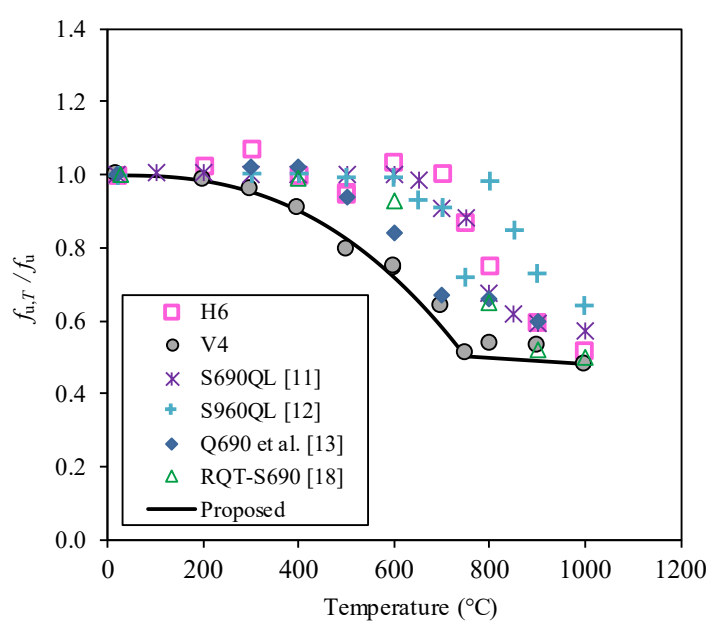

Fig. 10. Proposed ultimate strength retention factors for high strength steels.

The unified equation, which was proposed by Chen and Young [19] for mechanical properties of stainless steels at elevated temperatures, is 
employed herein for the mechanical properties of high strength steels after exposure to fire. The proposed predictive equations for post-fire Young's modulus, post-fire yield stress and postfire ultimate strength are expressed in Eqs. (1)(3), respectively.

$$
\begin{aligned}
& \frac{E_{T}}{E}=a-\frac{(T-b)^{n}}{c} \\
& \frac{f_{\mathrm{y}, T}}{f_{\mathrm{y}}}=a-\frac{(T-b)^{n}}{c} \\
& \frac{f_{\mathrm{u}, T}}{f_{\mathrm{u}}}=a-\frac{(T-b)^{n}}{c}
\end{aligned}
$$

in which, $T$ is the temperature in ${ }^{\circ} \mathrm{C} ; a, b, c$ and $n$ are the coefficients as tabulated in Table 4 .

Table 4. Proposed post-fire retention factor coefficients for high strength steels.

\begin{tabular}{cccccc}
\hline & $T\left({ }^{\circ} \mathrm{C}\right)$ & $a$ & $b$ & $c$ & $n$ \\
\hline & $20<T \leq 600$ & 1 & 20 & $2.0 \times 10^{4}$ & 1 \\
$\frac{E_{T}}{E}$ & $600<T \leq 900$ & 0.971 & 60 & $9.5 \times 10^{2}$ & 1 \\
& $900<T \leq 100$ & 0 & 0 & & \\
& 0 & 0.655 & 0 & $1.0 \times 10^{4}$ & 1 \\
\hline \multirow{4}{f_{\mathrm{y},T}}{} & $20<T \leq 500$ & 1 & 20 & $3.0 \times 10^{4}$ & 1 \\
$f_{\mathrm{y}}$ & $500<T \leq 750$ & 0.984 & 50 & $1.6 \times 10^{6}$ & 2.5 \\
& $750<T \leq 100$ & 0.366 & 75 & $1.0 \times 10^{5}$ & 1 \\
\hline$\frac{f_{\mathrm{u}, T}}{f_{\mathrm{u}}}$ & $20<T \leq 750$ & 1 & 20 & $2.9 \times 10^{7}$ & 2.5 \\
\hline & $750<T \leq 100$ & 0.504 & 75 & $1.2 \times 10^{4}$ & 1 \\
\hline
\end{tabular}

Overall, the proposed predictive equations are capable of providing conservative predictions for the retention factors, as shown in Figs. 8-10. Therefore, the proposed prediction equations are suggested to be used for post-fire mechanical properties of cold-formed and hotrolled high strength steels with nominal yield stresses ranged from 690 to $960 \mathrm{MPa}$.

\section{Conclusions}

An experimental investigation on residual mechanical properties of cold-formed high strength steels after exposure to fire has been presented. The measured yield stresses $(0.2 \%$ proof stresses) of the cold-formed high strength steels without fire exposure were 673 and 991 $\mathrm{MPa}$. The specimens were exposed to 10 different elevated temperatures up to $1000{ }^{\circ} \mathrm{C}$ before cooled down to ambient temperature. Residual mechanical properties including Young's modulus, yield stress and ultimate strength were obtained from the coupon tests.

The cold-formed high strength steel materials regained more than about $90 \%$ of their original Young's moduli even after being exposed to $1000{ }^{\circ} \mathrm{C}$, while the post-fire yield stresses and ultimate strengths remained less than $60 \%$ after being exposed to elevated temperatures beyond $800{ }^{\circ} \mathrm{C}$. The post-fire retention factors for mechanical properties of cold-formed high strength steels were compared with the proposals in Gunalan and Mahendran [10] for cold-formed high strength steels as well as proposals in Qiang et al. [11, 12] and Li et al. [13] for hot-rolled high strength steels. Overall, it is shown that the predictive equations in the literature are not suitable to predict the residual strengths of the tested cold-formed high strength steels after exposure to fire. The cold-formed high strength steel data obtained in this study and the hotrolled high strength steel data reported by Qiang et al. [11, 12], Li et al. [13] and Chiew et al. [18] were used to propose residual mechanical properties for high strength steels after exposure to fire. It is illustrated that the proposed predictive equations are suitable for both coldformed and hot-rolled high strength steel materials with nominal yield stresses ranged from 690 to $960 \mathrm{MPa}$.

\section{References}

[1] Ma JL, Chan T-M, Young B. Material properties and residual stresses of cold-formed high strength steel hollow sections. Journal of Constructional Steel Research 2015;109:152165.

[2] Li HT, Young B. Material properties of coldformed high strength steel at elevated temperatures. Thin-Walled Structures 2017;115: 289-299.

[3] Chen J, Young B, Uy B. Behaviour of high strength structural steel at elevated temperatures. Journal of Structural Engineering 2006;132(12): 1948-1954.

[4] Qiang X, Bijlaard F, Kolstein H. Dependence of mechanical properties of high strength steel S690 on elevated temperatures. Construction and Building Materials 2012;30:73-79.

[5] Qiang X, Jiang X, Bijlaard FSK, Kolstein H. Mechanical properties and design recommendations of very high strength steel 
S960 in fire. Engineering Structures 2016;112: 60-70.

[6] Wang W, Liu B, Kodur V. Effect of temperature on strength and elastic modulus of high-strength steel. Journal of Materials in Civil Engineering 2013;25(2):174-182.

[7] Heidarpour A, Tofts NS, Korayem AH, Zhao XL, Hutchinson CR. Mechanical properties of very high strength steel at elevated temperatures. Fire Safety Journal 2014;64:27-35.

[8] Choi IR, Chung K-S, Kim D-H. Thermal and mechanical properties of high-strength structural steel HSA800 at elevated temperatures. Materials \& Design 2014;63:544-51.

[9] Xiong MH, Liew JYR. Mechanical properties of heat-treated high tensile structural steel at elevated temperatures. Thin-Walled Structures 2016;98:169-76.

[10]Gunalan S, Mahendran M. Experimental investigation of post-fire mechanical properties of cold-formed steels. Thin-Walled Structures 2014;84:241-254.

[11] Qiang X, Bijlaard FSK, Kolstein H. Post-fire mechanical properties of high strength structural steels S460 and S690. Engineering Structures 2012;35:1-10.

[12]Qiang X, Bijlaard FSK, Kolstein H. Post-fire performance of very high strength steel S960.
Journal of Constructional Steel Research 2013; 80:235-242.

[13]Li GQ, Lyu H, Zhang C. Post-fire mechanical properties of high strength Q690 structural steel. Journal of Constructional Steel Research 2017; 132:108-116.

[14] ASTM E 21. Standard test methods for elevated temperature tension tests of metallic materials. West Conshohocken, USA: American Society for Testing and Materials; 2009.

[15] McCann F, Gardner L, Kirk S. Elevated temperature material properties of cold-formed steel hollow sections. Thin-Walled Structures 2015;90:84-94.

[16] Wang YC. Steel and composite structures Behaviour and design for fire safety. London; 2002.

[17]Huang Y, Young B. The art of coupon tests. Journal of Constructional Steel Research 2014; 96:159-175.

[18] Chiew SP, Zhao MS, Lee CK. Mechanical properties of heat-treated high strength steel under fire/post-fire conditions. Journal of Constructional Steel Research 2014;9812-19.

[19]Chen J, Young B. Stress-strain curves for stainless steel at elevated temperatures. Engineering Structures 2006;28:229-239. 